\title{
Arterial and venous thromboembolism in chronic obstructive pulmonary disease: from pathogenic mechanisms to prevention and treatment
}

Anetta Undas received speaker fees from Bayer, Boehringer Ingelhein and Pfizer, manufacturers of NOACs.

\begin{abstract}
Chronic obstructive pulmonary disease (COPD) affects approximately $10 \%$ of adults older than 40 years and is an important causes of disability and death in elderly subjects. A large proportion of COPD patients suffer from cardiovascular comorbidities. Thromboembolic events contribute considerably to morbidity and mortality in these subjects. This review summarizes the current evidence regarding the association of COPD with increased thromboembolic risk. We discuss multiple mechanisms potentially linking these conditions and available pharmacological interventions reducing the risk of thrombotic arterial and venous events with special attention paid to new oral anticoagulants.
\end{abstract}

Key words: anticoagulants, COPD, cardiovascular, coagulation, thrombosis

Pneumonol Alergol Pol 2015; 83: 485-494

\section{Introduction}

Chronic obstructive pulmonary disease (COPD) is one of the most common chronic disorders in adults. The prevalence of the clinically overt COPD in subjects aged 40 years or more is estimated at about 10\% [1]. Furthermore, COPD prevalence is likely to rise because of aging of the Western societies and common exposure to tobacco smoke in the past those currently aged over 50 years.

The disease has substantial burden, evidenced both by direct influence on the affected individuals and socio-economic consequences on societies. In the European Union, COPD accounts for more than a half of health care expenditures on respiratory system diseases [2]. COPD is the third leading cause of death in the United States, and according to the World Health Organization prognosis until 2030, it will become the third leading cause of death also globally [3].

Knowledge on COPD evolved towards growing recognition of a systemic component of the disease and a role of its comorbidities. This is reflected by changes in the Global Initiative for Obstructive Lung Disease (GOLD) definition, which since 2006 has mentioned 'significant extrapulmonary effects' of COPD [4], and recently (since 2011) included the statement that 'comorbidities contribute to overall severity in individual patients' [2]. Cardiovascular diseases (CVDs) are the leading comorbidities in COPD and are responsible for a considerable proportion of hospitalizations and deaths in COPD subjects [4]. CVDs co-existing with COPD include venous thromboembolism (VTE), ischemic heart disease,

Address for correspondence: Anetta Undas, Jagiellonian University Medical College, ul. św. Anny 12, 31-008 Kraków, e-mail: mmundas@cyf-kr.edu.pl DOI: 10.5603/PiAP.2015.0078 
stroke, cardiac arrhythmias and heart failure. Epidemiological data indicate that CVDs occur more commonly in COPD subjects compared to controls without this disease. This association at least partially results from common risk factors, especially tobacco smoking, but there are data suggesting that COPD (or reduced lung function) represents an independent risk factor for CVDs. There is also a growing body of evidence documenting a prothrombotic state in COPD. This review summarizes the current evidence on increased thromboembolic risk in COPD and discusses potential mechanisms behind this link. We also provide data on established and new methods of pharmacological thromboprophylaxis.

\section{COPD and cardiovascular risk: epidemiological data}

Data from large clinical trials indicate that CVDs are among the most common causes of death in COPD subjects [5-7]. Observational studies have compellingly shown that diagnosis of COPD increases the risk of CVDs. This association was strongly supported by studies performed in a cohort of the Kaiser Permanente Medical Care Program recipients [8], a combined database from the Atherosclerosis Risk in Communities Study (ARIC), and the Cardiovascular Health Study (CHS) [9]. The Veterans Administration Medical System data demonstrated a significant association of COPD with an increased risk of coronary artery disease, heart failure and atrial fibrillation (AF) [10]. Common risk factors of COPD and CVDs necessitate caution in interpreting the results of observational studies, and indeed not in all of the published studies association of COPD diagnosis with increased CVDs risk was independent [11]. There is also a possibility that not COPD itself, but rather a reduction in lung function is responsible for the increased risk of CVDs. This hypothesis is supported by the studies demonstrating that both obstructive and restrictive patterns of lung function impairment are related to this increased risk [12]. On the other side, also subjects with normal lung function, but with symptoms of chronic bronchitis (chronic cough and sputum production) probably have increased CVDs risk. For example, chronic bronchitis symptoms were associated with increased risk of ischemic heart disease and ischemic heart disease-related death in a 13-year follow-up of a large Finnish cohort [13]. Furthermore, excessive $\mathrm{FEV}_{1}$ decline, which is a lung function variable related to disease ac- tivity in COPD, was also reported to be associated with increased risk of CVDs [14] and ischemic heart disease-related death [15].

Importantly, COPD worsens outcomes in subjects with confirmed ischemic heart disease. Such observations were reported for example in a prospectively followed cohort of patients after percutaneous coronary interventions [16] or in a retrospective study performed in patients after myocardial infarction [17]. In a recently published analysis of a large Swedish registry, COPD was likewise related to increased risk of death after myocardial infarction (crude rates: $24.6 \%$ vs. $13.8 \%$, multivariate analysis: HR 1.14, 95\% CI: 1.07 to 1.21) [18]. However, this study provided another interesting observation - similarly to other data, association of COPD with increased mortality was attenuated after adjustment for known confounders. The investigators also found that COPD patients less often received effective treatment, including thrombolysis, anticoagulation or $\beta$-blockers [18].

Of note, COPD is related to increased risk of $\mathrm{AF}$ as evidenced by several observational studies $[8,10]$. Long-term follow-up data from large cohorts (Copenhagen Heart Study [19], ARIC Study [20]) have also revealed increased risk of AF in individuals with reduced lung function. Some of the drugs commonly used in COPD $\left(\beta_{2}\right.$-agonists and theophylline) are known to increase the occurrence of AF. In a large registry of AF subjects, the presence of COPD correlated with worse prognosis (risk of death $26.9 \%$ vs. $12.3 \%$; HR 1.49, $\mathrm{p}<0.05$ ), yet the prevalence of stroke was similar regardless of the lung disease [21]. Recently, COPD has been demonstrated to represent an independent predictor of mortality in a large registry of the European AF subjects [22]. AF in COPD subjects is also recognized as a negative prognostic factor in the context of exacerbations with hypoxia, as suggested in the European Heart Rhythm Association/European Association of Cardio-Thoracic Surgery Guidelines [23]. Association of reduced lung function/COPD with increased risk of stroke was reported in the Copenhagen Heart Study [24] and the British Regional Heart Study [25]. In a study on large series of stroke subjects COPD was identified as an ischemic stroke risk factor [26].

Exacerbations of COPD pose direct threat to patients' life, have negative impact on patients' quality of life and accelerate lung function decline [2]. Thromboembolic events often impact the prognosis during exacerbations of COPD which has been reported to increase the risk of both 
myocardial infarction and stroke [27]. Venous thromboembolism (VTE) is also a common threat to hospitalized COPD patients. In a meta-analysis, pulmonary embolism prevalence was estimated to affect $20 \%$ of subjects with COPD exacerbation (25\% in hospitalized patients, and $3.3 \%$ of those treated in the emergency department), whereas deep vein thrombosis was detected in $12.4 \%$ of those patients [28]. COPD is associated with increased venous thromboembolic risk as shown in a number of epidemiological studies, including the Kaiser Permanente Medical Care Program data [8] and the General Practice Research Database [29]. VTE in COPD more often manifests as pulmonary embolism with increased risk of death as compared to individuals who do not suffer from COPD [30].

\section{Potential mechanisms}

There are several mechanisms that may link COPD with increased risk of thromboembolic complications: 1) systemic inflammation, 2) hypoxemia and enhanced oxidative stress, 3) endothelial dysfunction and 4) a prothrombotic state including platelet hyperreactivity, and augmented thrombin generation, in part associated with inflammatory state [4, 31]. Prolonged low-grade systemic inflammation in COPD is evidenced by increased serum concentrations of inflammatory markers such as C-reactive protein (CRP), fibrinogen, interleukin 6, interleukin 8 and tumor necrosis factor $\alpha$ [32]. Exacerbations, which are important events in the course of COPD, can lead to further elevation in systemic inflammation [33]. Low grade inflammation is a well-known risk factor for coronary heart disease [34] and CRP concentration is associated with increased risk of cardiovascular events and death [35] in COPD. The inflammatory process can influence coagulation in multiple ways. Some indirect evidence comes from in vitro studies. CRP may increase plasminogen activator inhibitor 1 activity [36] and decrease tissue plasminogen activator activity [37] and prostacyclin release [38] by endothelial cells. Ex vivo studies have identified multiple coagulation abnormalities in COPD. A study done in stable COPD subjects demonstrated higher rates of thrombin generation and formation as well as alterations in multiple plasma coagulation factors [39]. COPD subjects had a prominently elevated level of factor VIII, increased levels of prothrombin, factor V, VII, IX, but reduced concentration of tissue factor pathway inhibitor. Interestingly, these changes were observed irrespectively from the severity of COPD or concentrations of CRP and IL-6 [39]. The presence of circulating active tissue factor (TF) and activated factor XI (FXIa) was detected in a significant proportion (> 10\%) of stable COPD patients, indicating ongoing activation of the extrinsic coagulation pathway driven by exposure of $\mathrm{TF}$ [40]. In that study, COPD patients with detectable active TF and FXIa had significantly higher CRP, fibrinogen and prothrombin fragment $1+2(\mathrm{~F} 1+2)$ levels, a marker of thrombin generation, which suggests a close link of hypercoagulability with inflammation in this disease. Similar findings were described in patients with coronary artery disease, especially those with acute coronary syndrome [41]. Increased procoagulant activity of $\mathrm{TF}$ in COPD was also confirmed in another study [42]. Another abnormality identified in COPD were unfavorable alterations to plasma fibrin clot structure and function, involving the formation of denser networks, more resistant to lysis, as compared to well-matched controls [43]. Interestingly, elevated CRP was a strong and independent predictor of clot parameters in COPD, with improvement of these abnormalities following statin therapy despite negligible effects on CRP concentrations [43]. Similar changes were observed in stable ischemic heart disease [44]. Several studies documented increased plasma concentrations of markers of thrombin formation and/or activity (thrombin-antithrombin III complexes, fibrinopeptide A, F1 + 2) in COPD [45-50]. Of note, hypoxemic challenge caused an increase in thrombin-antithrombin III complexes and F1 +2 in subjects with COPD [46].

Several investigators have suggested that low-grade inflammation in COPD largely contributes to a prothrombotic state. Inflammation may act through increased platelet activity, as demonstrated by the correlation of CRP and IL-6 concentrations with immature platelet counts in patients with stable ischemic heart disease [47] or with increased platelet derived inflammatory transcripts in the Framingham Heart Study Offspring cohort data [48]. Increased circulating platelet-monocyte aggregates, a well-established marker of platelet activation, were demonstrated in subjects with both stable and exacerbated COPD [49]. It was suggested that low grade inflammation can cause thromboxane dependent platelet activation [50]. In stable COPD patients urinary levels of stable thromboxane metabolite (11-dehydro-TXB ${ }_{2}$ ) were elevated, correlated with partial arterial oxygen pressure and improved after short-term oxygen treatment [51]. $\beta$-throm- 
boglobulin, a specific marker of platelet activation, was elevated in some, but not all studies in COPD [45, 52], and increased platelet count was associated with increased mortality in patients following COPD exacerbation [53].

Reduced levels of vascular progenitor cells were reported in stable COPD [54] and it was suggested as a potential mechanism of increased CVD risk (via reduced vascular repair capacity) [55].

Systemic inflammation is associated with increased AF prevalence and with decreased chance to restore sinus rhythm [56]. In one randomized trial methylprednisolone treatment significantly decreased the risk of AF recurrence [57]. In the ARIC study, increased levels of factor VIII coagulant activity, fibrinogen and vWf were associated with a higher mortality risk in subjects both with and without AF, while the higher level of protein C - with lower risk of ischemic stroke [58]. Systemic inflammation potentially can also influence the AF risk by affecting cardiac function in COPD subjects [59].

\section{Management of COPD and thromboembolic risk}

\section{VTE in hospitalized COPD patients}

The risk of VTE in hospitalized COPD patients is increased, inter alia, due to bedrest, advanced age and concomitant diseases. This risk in hospitalized subjects can be assessed with the Padua Prediction Score, a tool validated in acutely ill medical patients (Table 1) [60]. VTE risk in those with "high-risk" score ( $\geq 4$ points) who had not received prophylaxis was estimated at $11 \%$, whereas in those with low risk it was only $0.3 \%$. A study done exclusively in hospitalized COPD patients provided evidence that a history of malignancy and previous episodes of VTE (included in the Padua Score) increase pulmonary embolism risk in this population [61]. A majority of patients hospitalized due to severity of COPD exacerbation will have increased risk of VTE, and also according to the GOLD guidelines they should receive thromboprophylaxis [2]. The ACCP Guidelines advocates low molecular weight heparin, low-dose unfractionated heparin or fondaparinux in these patients [62]. In those with high bleeding risk mechanical prophylaxis, first of all compression stockings, should be used.

Randomized trials addressing the effectiveness of heparin prophylaxis solely in COPD are sparse. A study done in subjects mechanically ventilated due to COPD exacerbation confirmed effectiveness of low molecular weight heparin in reducing VTE risk, yet without documented gain
Table 1. VTE risk assessment using the Padua Risk Score (adapted from [55])

\begin{tabular}{lc}
\hline Item & Points/risk \\
\hline $\begin{array}{l}\text { Cancer (metastases and/or chemio- or } \\
\text { radiotherapy in the previous 6 months }\end{array}$ & 3 \\
$\begin{array}{l}\text { Previous VTE (with the exclusion of su- } \\
\text { perficial vein thrombosis) }\end{array}$ & 3 \\
$\begin{array}{l}\text { Bedrest (with bathroom privileges) for } \\
\geq 3 \text { days }\end{array}$ & 3 \\
Thrombophilia & 3 \\
Recent ( $\leq 1$ months) trauma or surgery & 2 \\
Age $\geq 70$ years & 1 \\
Heart and/or respiratory failure & 1 \\
$\begin{array}{l}\text { Acute myocardial infarction or } \\
\text { ischemic stroke }\end{array}$ & 1 \\
Acute infection and/or rheumatologic & 1 \\
disorder & \\
BMI $\geq 30$ kg/m ${ }^{2}$ & 1 \\
Ongoing hormonal treatment & 1 \\
& $\geq 4$ points suggesting \\
\hline VTE - venous thromboembolism; BMl - body mass index &
\end{tabular}

in survival [63]. Evidence indicates that COPD patients should receive thromboprophylaxis like other medical hospitalized patients if their risk of VTE is increased unless there are contraindications e.g. active bleeding.

Unarguably, all hospitalized COPD subjects should be screened for signs and symptoms of deep vein thrombosis/pulmonary embolism. Risk of pulmonary embolism in COPD subjects presenting to emergency department with pulmonary exacerbations was $6.2 \%$ in those with clinical suspicion vs. $1.3 \%$ in those without. Diagnostic performance of D-dimer as well as spiral computed tomography in the diagnostic work-up of pulmonary embolism is not influenced by COPD exacerbation [64].

There is no data to support thromboprophylaxis in stable COPD subjects outside specific indications. The 2012 ACCP guidelines recommend against routine use of thromboprophylaxis in chronically immobilized patients residing at home, which refers also to subjects with advanced COPD. Despite in the most severe COPD patients additional risk factors such as steroid therapy or respiratory insufficiency may further increase VTE risk, clinical trial assessing low molecular weight heparin in stable, severe COPD subjects on long term oxygen therapy has not demonstrated survival benefit, however it was underpowered 
and had low quality [65]. Taken together, decision on thromboprohylaxis at home should be taken on an individual basis.

The decision on the type of prophylaxis used in acutely ill subjects (pharmacotherapy vs. mechanical methods) is mostly based on the bleeding risk assessment. Multiple risk factors of in-hospital bleeding were identified: gastrointestinal ulcer, low platelet count, bleeding history, advanced age ( $\geq 85$ years), hepatic or renal failure, rheumatic disease or cancer) [62]. Of those, active gastroduodenal ulcer, prior bleeding and low platelet count are the strongest predictors of bleeding [66]. Advanced age, which refers to most COPD subjects, also increases bleeding risk while on heparin. Systemic steroid therapy often used in COPD exacerbations is another factor that elevates the risk of gastrointestinal bleeding. The 2012 ACCP guidelines advocate to consider patients to have increased bleeding risk if they have one of the above mentioned factors with strong influence on bleeding risk or multiple risk factors and recommend against routine use of pharmacologic prophylaxis in those subjects. Available means of prophylaxis in patients with high bleeding risk comprise graduated compression stockings or intermittent pneumatic compression.

\section{Oral anticoagulants in COPD}

The most common indication for long-term oral anticoagulation in COPD is co-existent AF. Anticoagulation is generally recommended in those with intermediate or high risk of stroke defined as at least 1 point in the $\mathrm{CHA}_{2} \mathrm{DS}_{2}$-VASc score (Table 2) [67].

COPD subjects with AF (paroxysmal, persistent or permanent) due to frequent other comorbidities and/or advanced age usually fall into the high-risk category. In a large registry of AF subjects, those with COPD significantly more often had $\mathrm{CHA}_{2} \mathrm{DS}_{2}$-VASc score $\geq 2(81 \%$ vs. $65 \%$ ) [21]. Both, vitamin $\mathrm{K}$ antagonists (VKA) and non-vitamin $\mathrm{K}$ oral anticoagulants or novel oral anticoagulants (NOACs) effectively reduce the risk of ischemic stroke and systemic thromboembolism by about $80 \%$, as compared to up to $30 \%$ reduction on aspirin alone [68]. The VKA use requires regular laboratory control of anticoagulant effect and thoughtful avoiding of dietary changes and numerous drug interactions, which is often challenging, especially during COPD exacerbations. Multiple drugs, including commonly used antibiotics (macrolides [in particular clarithromycin], tetracyclines, cefuroxime,
Table 2. $\mathrm{CHA}_{2} \mathrm{DS}_{2}$-VASc scoring system in the assessment of thromboembolic risk in AF subjects (adapted from [81])

\begin{tabular}{lc}
\hline Item & Points \\
\hline Congestive heart failure/left ventricular dysfunction & 1 \\
Hypertension & 2 \\
Age $\geq 75$ years & 2 \\
Diabetes & 1 \\
Prior stroke or transient ischemic attack or systemic & 2 \\
embolism & \\
Vascular disease (prior myocardial infarction, peri- & 1 \\
pheral artery disease or aortic plaque) & \\
Age $64-74$ years & 1 \\
Female sex & 1 \\
\hline 0 point - very low risk, 1 point - moderate risk, $\geq 2$ points — high risk
\end{tabular}

cefoperazone, fluorochinolones, metronidazole, trimethoprim/sulfamethoxazole) influence VKA metabolism, leading to elevation of INR above $3-4$, especially if the therapy lasts more than 5-7 days together with reduced vitamin $\mathrm{K}$ intake $[69,70]$. Thus, NOACs may constitute a preferred alternative to VKA in these subjects, especially given the current recommendation to choose this option in Europe.

NOACs currently available in Europe comprise dabigatran (thrombin inhibitor), apixaban and rivaroxaban (activated FX inhibitors). These drugs were directly compared to VKA in a few large randomized clinical trials in non-valvular AF patients, including the open-label RE-LY Study [71], the ARISTOTLE Study aimed to compare apixaban and warfarin [72] and the ROCKET AF trial [73]. Similar results were published for edoxaban, a NOAC which was approved in Europe in January 2015 [74]. These large clinical trials provided strong evidence for NOACs effectiveness and safety; they are non-inferior to warfarin.

No specific studies compared NOACs with VKA in COPD subjects, yet a significant number of COPD subjects participated in the above mentioned trials [71-74]. This proportion was about $10 \%$, based on the published reports from the ROCKET-AF Trial (11\% of all participants) [85] and the ARISTOTLE trial (9\% of those with previous stroke or transient ischemic attack) [75]. The European Society of Cardiology guidelines consider NOACs as the preferred option to VKA in non-valvular $\mathrm{AF}$, especially when starting anticoagulation in previously untreated subjects or in those who experienced thromboembolism while on VKA [23]. Switching patients with optimal 
anticoagulation on VKA to NOACs is not justified, also in COPD patients free of bleeding tendency.

Potential advantages of NOACs over VKA [76] may be particularly relevant in COPD subjects. NOACs are used in fixed doses without need for monitoring the pharmacological effect and are more convenient when anticoagulation is to be stopped or modified [77]. These situations comprise the need for surgery/invasive procedure. When bleeding risk is high, stopping the drug for $\geq 4$ half-life time (usually 2-3 days - Table 3 ) is recommended before the elective procedure [78]. When assessment of NOACs anticoagulation effect is necessary, routine coagulation tests are less informative than prothrombin time in case of VKA treatment. Factor Xa inhibitors, especially rivaroxaban, do prolong prothrombin time, yet this effect is variable and probably useful clinically only for qualitative assessment of rivaroxaban's effect [78]. APTT provides only imprecise qualitative assessment of dabigatran's effect. Rivaroxaban and apixaban need anti-Xa assay for quantitative assessment. The effect of apixaban can be qualitatively evaluated with modified PT, while dabigatran — with dilute thrombin time or anti-factor II assay. When necessary and feasible, concentration of NOACs can be directly measured in plasma $[79,80]$.

NOACs differ in pharmacological characteristics (Table 3), which may have important clinical consequences. Impaired renal function may need dose reduction or is a contraindication if chronic disease is in stage 4 or 5 [81]. These factors should be considered when treating COPD subjects, often encumbered with multiple comorbidities.

NOACs generally do not interact with antibiotics, except rifampicin, erythromycin and clarithromycin [81]. Both clarithromycin and erythromycin interact with rivaroxaban and dabigatran, increasing NOAC's effect by approximately $20-50 \%$, while rifampicin decreases the effect of rivaroxaban and increases the one of dabigatran and apixaban [78]. Some other drug interactions of NOACs include amiodarone, verapamil, diltiazem, azole antimycotics, cyclosporine, tacrolimus, HIV protease inhibitors and carbamazepine [82]. Of those interactions with antiarrhythmics, the most important for COPD

Table 3. Pharmacological properties of NOACs (reprinted with permission [76])

\begin{tabular}{|c|c|c|c|c|}
\hline & Warfarin & Dabigatran etexilate $^{a}$ & Rivaroxaban & Apixaban \\
\hline Mode of action & $\begin{array}{c}\downarrow \text { synthesis of vitamin } \\
\text { K-dependent coagulation } \\
\text { factors }\end{array}$ & $\begin{array}{c}\text { Direct selective and re- } \\
\text { versible thrombin inhibitor }\end{array}$ & $\begin{array}{l}\text { Direct selective and re- } \\
\text { versible activated factor } \\
\text { X inhibitor }\end{array}$ & $\begin{array}{l}\text { Direct selective and re- } \\
\text { versible activated factor } \\
\text { X inhibitor }\end{array}$ \\
\hline $\begin{array}{l}\text { Time to peak plasma con- } \\
\text { centration }\end{array}$ & $\begin{array}{c}90 \text { min (peak action after } \\
4-5 d)\end{array}$ & $0.5-2 \mathrm{~h}$ & $2-4 \mathrm{~h}$ & $1-4 h$ \\
\hline Half-life & $36-42 \mathrm{~h}$ & $12-14 \mathrm{~h}$ & $\begin{array}{c}5-9 \mathrm{~h} \text { (young) } \\
-13 \mathrm{~h} \text { (age }>65 \text { years) }\end{array}$ & $8-13 \mathrm{~h}$ \\
\hline $\begin{array}{l}\text { Substrate of P-glycopro- } \\
\text { tein transporter }\end{array}$ & No & Yes & Yes & Yes \\
\hline $\begin{array}{l}\text { Substrate of CYP en- } \\
\text { zymes }\end{array}$ & Yes (CYP3A4, CYP2C9) & No & Yes (CYP3A4/5, CYP2J2) & Yes (CYP3A4, CYP2C9) \\
\hline Route of elimination & Various $^{b}$ & $80 \%$ renal & $\begin{array}{c}66 \% \text { renal }(33 \% \text { unchan- } \\
\text { ged) }\end{array}$ & $25 \%$ renal \\
\hline Protein binding & $99 \%$ & $35 \%$ & $90 \%$ & $90 \%$ \\
\hline Basic daily dose in AF & $\begin{array}{c}\sim 5 \mathrm{mg}(1-18 \mathrm{mg}) \text { target } \\
\text { INR } 2-3\end{array}$ & $2 \times 150 \mathrm{mg}$ & $1 \times 20 \mathrm{mg}$ & $2 \times 5 \mathrm{mg}$ \\
\hline Reduced daily dose & Not applicable & $2 \times 110 \mathrm{mg}^{\mathrm{c}}$ & $1 \times 15 \mathrm{mg}$ & $2 \times 2.5 \mathrm{mg}$ \\
\hline $\begin{array}{l}\text { Indications for reduced } \\
\text { dosage }\end{array}$ & Not applicable & $\begin{array}{l}\text { - creatinine clearance } \\
30-49 \mathrm{~mL} / \mathrm{min} \\
\text { - HAS-BLED } \geq 3 \text { points } \\
\text { - age } \geq 80 \text { years } \\
\text { - co-administration of } \\
\text { verapamil }\end{array}$ & $\begin{array}{l}\text { - creatinine clearance } \\
30-49 \mathrm{~mL} / \mathrm{min} \\
\text { - HAS-BLED } \geq 3 \text { points }\end{array}$ & $\begin{array}{c}\text { - creatinine } \geq 133 \mu \mathrm{M} \\
\text { - age } \geq 80 \text { years } \\
\text { - body weight } \leq 60 \mathrm{~kg} \\
\text { ( } 2 \text { or } 3 \text { criteria MET) }\end{array}$ \\
\hline
\end{tabular}

${ }^{\mathrm{a} A}$ prodrug that undergoes biotransformation to the active molecule, dabigatran, by esterases; ${ }^{\mathrm{b}}$ The anticoagulant effect of warfarin is eliminated through synthesis of functionally active coagulation factors rather than through elimination of warfarin; coagulation factor synthesis is hastened by exogenous vitamin $\mathrm{K}$; ' In the United States: $2 \times 75 \mathrm{mg}$ daily $(2 \times 110 \mathrm{mg}$ not approved $)$ 
subjects are verapamil and amiodarone that increase dabigatran's effect and diltiazem that increases apixaban's effect.

Bleeding complications are the major threat for both, patients on anticoagulation and their physicians. Assessment of the bleeding risk with the validated HAS-BLED scale is helpful in managing subjects with AF (Table 4). The risk of bleeding increases with age, which is important as most of COPD subjects are in advanced age [83]. COPD patients often have poor adherence to treatment [84] and those treated with VKA should be supervised thoroughly, as poor control of therapy is another risk factor for bleeding [85]. Most experts consider NOACs as a safer therapeutic option in COPD patients compared with VKA. Large trials comparing NOACs with VKA identified multiple risk factors associated with increased bleeding risk. Of note, in a ROCKET AF trial history of COPD was one of bleeding risk factors [86]. Other risk factors independently associated with major bleeding risk included older age, baseline diastolic blood pressure (DBP) $\geq 90$ $\mathrm{mm} \mathrm{Hg}$, gastrointestinal bleeding, prior acetylsalicylic acid use, and anemia; female sex and DBP $<90 \mathrm{~mm} \mathrm{Hg}$ were associated with a decreased risk. Analysis of the ARISTOTLE trial data with apixaban identified older age, prior hemorrhage, prior stroke or transient ischemic attack, diabetes, low creatinine clearance, decreased hematocrit, use of acetylsalicylic acid or other nonsteroidal anti-inflammatory drugs as risk factors for bleeding, COPD was not a risk factor [87]. Subjects with COPD, usually presenting with multiple comorbidities, often have increased bleeding risk.

\section{Antiplatelet drugs in COPD}

Antiplatelet therapy reduces cardiovascular risk in the prevention and treatment of atherothrombotic events [88]. Indications for antiplatelet therapy are not different in COPD when compared to subjects with normal lung function, yet there are some data, indicating that COPD subjects are less likely to receive proper treatment. A study based on Krakow Registry of Acute Coronary Syndromes data reported that patients with COPD less often received antiplatelet therapy (aspirin and clopidogrel) during hospital stay [89]. Furthermore, they have higher risk of in-hospital death, and multivariate analysis confirmed COPD diagnosis as an independent predictor of in-hospital death. A recently published observational study identified association of aspirin use with improved survival after COPD exacerbation [53] and it was suggested that routine use of low dose
Table 4. HAS-BLED score to assess bleeding risk in patients with atrial fibrillation (adapted from [81])

\begin{tabular}{lc}
\hline Item & Points/risk \\
\hline Hypertension (systolic pressure $>160 \mathrm{~mm} \mathrm{Hg}$ ) & 1 \\
Abnormal renal function & 1 \\
Abnormal liver function & 1 \\
Age $\geq 65$ years & 1 \\
Prior stroke & 1 \\
Prior bleeding & 1 \\
Labile INRs (e.g. time in therapeutic range $<60 \%)$ & 1 \\
Taking other drugs at the same time (e.g. ASA, & 1 \\
NSAIDs) & 1 \\
Alcohol intake & $\geq 3$ points \\
& means \\
& a high risk of \\
bleeding
\end{tabular}

aspirin should be considered after COPD exacerbations [90].

\section{Conclusions}

A large body of epidemiological data supports hypothesis that COPD increases venous and arterial thromboembolic risk. Diverse coagulation abnormalities were identified in the COPD ranging from those associated with systemic inflammation and hypoxemia to a hypercoagulable state. Further studies are needed to fully elucidate these mechanisms. Unarguably, in every COPD patient emphasis should be placed on thromboprophylaxis when necessary and CVDs should be searched for with implementation of effective pharmacotherapy, once the diagnosis is established. New therapeutic modalities have the opportunity to improve outcomes and possibly prolong patients' lives.

\section{Conflict of interest}

The authors declare no conflict of interest.

\section{References:}

1. Buist AS, McBurnie MA, Vollmer WM et al. International variation in the prevalence of COPD (The BOLD Study): a population-based prevalence study. Lancet 2007; 370: 741-750.

2. From the Global Strategy for the Diagnosis, Management and Prevention of COPD, Global Initiative for Chronic Obstructive Lung Disease (GOLD) 2014. Available from: http://www. goldcopd.org/

3. World Health Organization data: http://www.who.int/respiratory/copd/burden/en/ 
4. http://www.goldcopd.org/Guidelines/guidelines-global-strategy-for-diagnosis-management-2006.html

5. Anthonisen NR, Connett JE, Kiley JP et al. Effects of smoking intervention and the use of an inhaled anticholinergic bronchodilator on the rate of decline of FEV1: the Lung Health Study. JAMA 1994; 272: 1497-1505.

6. Celli B, Decramer M, Kesten S, Liu D, Mehra S, Tashkin DP. Mortality in the 4-year trial of tiotropium (UPLIFT) in patients with chronic obstructive pulmonary disease. Am J Respir Crit Care Med 2009; 180: 948-955. doi: 10.1164/rccm.200906-08760C.

7. McGarvey LP, John M, Anderson JA et al. Ascertainment of cause-specific mortality in COPD: operations of the TORCH Clinical Endpoint Committee. Thorax 2007; 62: 411-415.

8. Sidney S, Sorel M, Quesenberry CP Jr, DeLuise C, Lanes S, Eisner MD. COPD and incident cardiovascular disease hospitalizations and mortality: Kaiser Permanente Medical Care Program. Chest 2005; 128: 2068-2075.

9. Mannino DM, Thorn D, Swensen A, Holguin F. Prevalence and outcomes of diabetes, hypertension and cardiovascular disease in COPD. Eur Respir J 2008; 32: 962-969. doi: 10.1183/09031936.00012408.

10. Mapel DW, Dedrick D, Davis K. Trends and cardiovascular co-morbidities of COPD patients in the Veterans Administration Medical System, 1991-1999. COPD 2005; 2: 35-41.

11. Lange P, Mogelvang R, Marott JL, Vestbo J, Jensen JS. Cardiovascular morbidity in COPD: A study of the general population. COPD 2010; 7: 5-10.

12. Ford ES, Wheaton AG, Mannino DM et al. Elevated cardiovascular risk among adults with obstructive and restrictive airway functioning in the United States: a cross-sectional study of the National Health and Nutrition Examination Survey from 2007-2010. Respir Res 2012; 13: 115-126. doi: 10.1186/14659921-13-115.

13. Jousilahti P, Vartiainen E, Tuomilehto J, Puska P. Symptoms of chronic bronchitis and the risk of coronary disease. Lancet 1996; 348: 567-572.

14. Engström G, Hedblad B, Janzon L, Valind S. Respiratory decline in smokers and ex-smokers - an independent risk factor for cardiovascular disease and death. J Cardiovasc Risk 2000; 7: $267-272$.

15. Tockman MS, Pearson JD, Fleg JL et al. Rapid decline in $\mathrm{FEV}_{1}$ a new risk factor for coronary heart disease mortality. Am Respir Crit Care Med 1995; 151: 390-398.

16. Berger JS, Sanborn TA, Sherman W, Brown DL. Effect of chronic obstructive pulmonary disease on survival of patients with coronary heart disease having percutaneous coronary intervention. Am J Cardiol 2004; 94: 649-651.

17. Stefan MS, Bannuru RR, Lessard D, Gore JM, Lindenauer PK, Goldberg RJ. The impact of COPD on management and outcomes of patients hospitalized with acute myocardial infarction: a 10-year retrospective observational study. Chest 2012 141: 1441-1448. doi: 10.1378/chest.11-2032.

18. Andell P, Koul S, Martinsson A et al. Impact of chronic obstructive pulmonary disease on morbidity and mortality after myocardial infarction. Open Heart 2014; doi:10.1136/ openhrt-2013-000002.

19. Buch P, Friberg J, Scharling H, Lange P, Prescott E. Reduced lung function and risk of atrial fibrillation in the Copenhagen City Heart Study. Eur Respir J 2003; 21: 1012-1016.

20. Li J, Agarwal SK, Alonso A et al. Airflow obstruction, lung function, and incidence of atrial fibrillation: the Atherosclerosis Risk in Communities (ARIC) study. Circulation 2014; 129: 971-980. doi: 10.1161/CIRCULATIONAHA.113.004050.

21. Huang B, Yang Y, Zhu J et al. Clinical characteristics and prognostic significance of chronic obstructive pulmonary disease in patients with atrial fibrillation: results from a multicenter atria fibrillation registry study. J Am Med Dir Assoc 2014; 15: 576-581. doi: 10.1016/j.jamda.2014.04.009.

22. Lip GY, Laroche C, Ioachim PM et al. Prognosis and treatment of atrial fibrillation patients by European cardiologists: one year follow-up of the EURObservational Research Programme-Atrial Fibrillation General Registry Pilot Phase (EORP-AF Pilot registry). Eur Heart J 2014; 35: 3365-3376. doi: 10.1093/eurheartj/ehu374.
23. Camm AJ, Kirchhof P, Lip GY et al. Guidelines for the management of atrial fibrillation. Eur Heart J 2010; 31: 2369-2429. doi: 10.1093/eurheartj/ehq278.

24. Truelsen T, Prescott E, Lange P, Schnohr P, Boysen G. Lung function and risk of fatal and non-fatal stroke. The Copenhagen City Heart Study. Int J Epidemiol 2001; 30: 145-151.

25. Wannamethee G, Shaper AG, Ebrahim S. Respiratory function and risk of stroke. Stroke 1995; 26: 2004-2010.

26. Arboix J, Morcillo C, Garcia-Eroles L, Oliveres M, Massons J, Targa C. Different vascular risk factor profiles in ischemic stroke subtypes: a study from the "Sagrat Cor Hospital of Barcelona Stroke Registry". Acta Neurol Scand 2000; 102 : 264-270.

27. Donaldson GC, Hurst JR, Smith CJ et al. Increased risk of myocardial infarction and stroke following exacerbation of COPD. Chest 2010; 137: 1091-1097. doi: 10.1378/chest.09-2029.

28. Rizkallah J, Man SF, Sin DD. Prevalence of pulmonary embolism in acute exacerbations of COPD: a systematic review and metaanalysis. Chest 2009; 135: 786-793. doi: 10.1378/ chest.08-1516.

29. Schneider C, Bothner U, Jick SS, Meier CR. Chronic obstructive pulmonary disease and the risk of cardiovascular diseases. Eur J Epidemiol 2010; 25: 253-260. doi: 10.1007/s10654-0109435-7

30. Bertoletti L, Quenet S, Mismetti P et al.; RIETE Investigators. Clinical presentation and outcome of venous thromboembolism in COPD. Eur Respir J 2012; 39: 862-868. doi: 10.1183/09031936.00058811.

31. Barnes PJ, Celli BR. Systemic manifestations and comorbidities of COPD. Eur Respir J 2009; 33: 1165-1185. doi: 10.1183/09031936.00128008.

32. Gan WQ, Man SF, Senthilselvan A, Sin DD. Association between chronic obstructive pulmonary disease and systemic inflammation: a systematic review and a meta-analysis. Thorax 2004; 59: 574-580.

33. Wedzicha JA, Seemungal TA, MacCallum PK et al. Acute exacerbations of chronic obstructive pulmonary disease are accompanied by elevations of plasma fibrinogen and serum IL-6 levels. Thromb Haemost 2000; 84: 210-215.

34. Danesh J, Whincup P, Walker $\mathrm{M}$ et al. Low grade inflammation and coronary heart disease: prospective study and updated meta-analyses. BMJ 2000; 321: 199-204.

35. Man SF, Connett JE, Anthonisen NR, Wise RA, Tashkin DP Sin DD. C-reactive protein and mortality in mild to moderate chronic obstructive pulmonary disease. Thorax 2006; 61 849-853.

36. Devaraj S, Xu DY, Jialal I. C-reactive protein increases plasminogen activator inhibitor-1 expression and activity in human aortic endothelial cells: implications for the metabolic syndrome and atherothrombosis. Circulation 2003; 107: 398-404.

37. Singh U, Devaraj S, Jialal I. C-reactive protein decreases tissue plasminogen activator activity in human aortic endothelial cells: evidence that C-reactive protein is a procoagulant. Arterioscler Thromb Vasc Biol 2005; 25: 2216-2221.

38. Venugopal SK, Devaraj S, Jialal I. C-reactive protein decreases prostacyclin release from human aortic endothelial cells. Circulation 2003; 108: 1676-1678.

39. Undas A, Jankowski M, Kaczmarek P, Sladek K, Brummel-Ziedins K. Thrombin generation in chronic obstructive pulmonary disease: dependence on plasma factor composition. Thromb Res 2011; 128: 24-28. 10.1016/j.thromres.2011.05.004.

40. Jankowski M, Undas A, Kaczmarek P, Butenas S. Activated factor XI and tissue factor in chronic obstructive pulmonary disease: links with inflammation and thrombin generation. Thromb Res 2011; 127: 242-246. doi: 10.1016/j.thromres.2010.11.005.

41. Butenas S, Undas A, Gissel MT, Szuldrzynski K, Zmudka K Mann KG. Factor XIa and tissue factor activity in patients with coronary artery disease. Thromb Haemost 2008; 99: 142-149. doi: 10.1160/TH07-08-0499.

42. Vaidyula VR, Criner GJ, Grabianowski C, Rao AK. Circulating tissue factor procoagulant activity is elevated in stable moderate to severe chronic obstructive pulmonary disease. Thromb Res 2009; 124: 259-261. doi: 10.1016/j.thromres.2008.12.030. 
43. Undas A, Kaczmarek P, Sladek K et al. Fibrin clot properties are altered in patients with chronic obstructive pulmonary disease. Beneficial effects of simvastatin treatment. Thromb Haemost 2009; 102: 1176-1182. doi: 10.1160/TH09-02-0118.

44. Undas A, Plicner D, Stepien E et al. Altered fibrin clot structure in patients with advanced coronary artery disease: a role of C-reactive protein, lipoprotein(a), and homocysteine. J Thromb Haemost 2007; 5: 1988-1990.

45. Ashitani J, Mukae H, Arimura Y, Matsukura S. Elevated plasma procoagulant and fibrinolytic markers in patients with chronic obstructive pulmonary disease. Intern Med 2002; 41: 181-185.

46. Sabit R, Thomas P, Shale DJ, Collins P, Linnane SJ. The effects of hypoxia on markers of coagulation and systemic inflammation in patients with COPD. Chest 2010; 138: 47-51.

47. Larsen SB, Grove EL, Hvas AM, Kristensen SD. Platelet turnover in stable coronary artery disease - influence of thrombopoietin and low-grade inflammation. PLoS One 2014; 9: e85566. doi: 10.1371/journal.pone.0085566

48. McManus DD, Beaulieu LM, Mick E et al. Relationship among circulating inflammatory proteins, platelet gene expression, and cardiovascular risk. Arterioscler Thromb Vasc Biol 2013; 33: 2666-2673. doi: 10.1161/ATVBAHA.112.301112.

49. Maclay JD, McAllister DA, Johnston S et al. Increased platelet activation in patients with stable and acute exacerbation of COPD. Thorax 2011; 66: 769-774. doi: 10.1136/ thx.2010.157529.

50. Davì G, Patrono C. Platelet activation and atherothrombosis. N Engl J Med 2007; 357: 2482-2494.

51. Davì G, Basili S, Vieri M et al. Enhanced thromboxane biosynthesis in patients with chronic obstructive pulmonary disease. The Chronic Obstructive Bronchitis and Haemostasis Study Group. Am J Respir Crit Care Med 1997; 156: 1794-1799.

52. Kanazawa H, Asai K, Nomura S. Changes in circulating thrombomodulin levels with exercise in patients with chronic obstructive pulmonary disease. Respirology 2007; 12: 670-674

53. Harrison MT, Short P, Williamson PA, Singanayagam A, Chalmers JD, Schembri S. Thrombocytosis is associated with increased short and long term mortality after exacerbation of chronic obstructive pulmonary disease: a role for antiplatelet therapy? Thorax 2014; 69: 609-615. doi: 10.1136/thoraxjnl-2013-203996.

54. Palange P, Testa U, Huertas A et al. Circulating haemopoietic and endothelial progenitor cells are decreased in COPD. Eur Respir J 2006; 27: 529-541.

55. Barberà JA, Peinado VI. Vascular progenitor cells in chronic obstructive pulmonary disease. Proc Am Thorac Soc 2011; 8: 528-534. doi: 10.1513/pats.201101-010MW

56. Issac TT, Dokainish H, Lakkis NM. Role of inflammation in initiation and perpetuation of atrial fibrillation: a systematic review of the published data. J Am Coll Cardiol 2007; 50: 2021-2028.

57. Dernellis J, Panaretou M. Relationship between C-reactive protein concentrations during glucocorticoid therapy and recurrent atrial fibrillation. Eur Heart J 2004; 25: 1100-1107.

58. Alonso A, Tang W, Agarwal SK, Soliman EZ, Chamberlain AM, Folsom AR. Hemostatic markers are associated with the risk and prognosis of atrial fibrillation: the ARIC study. Int J Cardiol 2012; 155: 217-222. doi: 10.1016/j.ijcard.2010.09.051.

59. Kazmierczak M, Ciebiada M, Pękala-Wojciechowska A, Pawłowski M, Pietras T, Antczak A. Correlation of inflammatory markers with echocardiographic parameters of left and right ventricular function in patients with chronic obstructive pulmonary disease and cardiovascular diseases. Pol Arch Med Wewn 2014; 124: 290-297.

60. Barbar S, Noventa F, Rossetto V et al. A risk assessment model for the identification of hospitalized medical patients at risk for venous thromboembolism: the Padua Prediction Score. J Thromb Haemost 2010; 8: 2450-2457. doi: 10.1111/j.15387836.2010.04044.x.

61. Tillie-Leblond I, Marquette CH, Perez T et al. Pulmonary embolism in patients with unexplained exacerbation of chronic obstructive pulmonary disease: prevalence and risk factors. Ann Intern Med 2006; 144: 390-396.
62. Kahn SR, Lim W, Dunn AS et al. Prevention of VTE in Nonsurgical Patients: Antithrombotic Therapy and Prevention of Thrombosis, 9th ed: American College of Chest Physicians Evidence-Based Clinical Practice Guidelines. Chest 2012; 141: 195S-226S. doi: 10.1378/chest.11-2296.

63. Fraisse F, Holzapfel L, Couland JM et al. Nadroparin in the prevention of deep vein thrombosis in acute decompensated COPD. The Association of Non-University Affiliated Intensive Care Specialist Physicians of France. Am J Respir Crit Care Med 2000; 161: 1109-1114.

64. Hartmann IJ, Hagen PJ, Melissant CF, Postmus PE, Prins MH Diagnosing acute pulmonary embolism: effect of chronic obstructive pulmonary disease on the performance of D-dimer testing, ventilation/perfusion scintigraphy, spiral computed tomographic angiography, and conventional angiography. ANTELOPE Study Group. Advances in New Technologies Evaluating the Localization of Pulmonary Embolism. Am J Respir Crit Care Med 2000; 162: 2232-2237.

65. Modesto-Alapont M, Nauffal-Manzur D, Ansótegui-Barrera E et al. Can home prophylaxis for venous thromboembolism reduce mortality rates in patients with chronic obstructive pulmonary disease? Arch Bronconeumol 2006; 42: 130-134.

66. Narum S, Westergren T, Klemp M. Corticosteroids and risk of gastrointestinal bleeding: a systematic review and meta-analysis. BMJ Open 2014; 4: e004587. doi: 10.1136/bmjopen-2013-004587

67. You JJ, Singer DE, Howard PA et al. Antithrombotic Therapy Therapy for atrial fibrillation: antithrombotic therapy and prevention of thrombosis, 9th ed: American College of Chest Physicians Evidence-Based Clinical Practice Guidelines. Chest 2012; 141: 531S-575S. doi: 10.1378/chest.11-2304

68. Niewiada M, Czlonkowka A. Prevention of ischemic stroke in clinical practice: a role of internists and general practitioners. Pol Arch Med Wewn 2014; 124: 540-548.

69. Holbrook AM, Pereira JA, Labiris R, McDonald H, Douketis JD, Crowther M, Wells PS. Systematic overview of warfarin and its drug and food interactions. Arch Intern Med 2005; 165: 1095-1106.

70. Clark NP, Delate T, Riggs CS et al. Warfarin interactions with antibiotics in the ambulatory care setting. JAMA Intern Med 2014; 174: 409-416. doi: 10.1001/jamainternmed.2013.13957.

71. Connolly SJ, Ezekowitz MD, Yusuf S et al.; RE-LY Steering Committee and Investigators. Dabigatran versus warfarin in patients with atrial fibrillation. N Engl J Med 2009; 361: 1139-1151. doi: 10.1056/NEJMoa0905561

72. Granger CB, Alexander JH, McMurray JJ et al. Apixaban versus warfarin in patients with atrial fibrillation. N Engl J Med 2011; 365: 981-992. doi: 10.1056/NEJMoa1107039.

73. Patel MR, Mahaffey KW, Garg J et al. Rivaroxaban versus warfarin in nonvalvular atrial fibrillation. N Engl J Med 2011; 365 : 883-891. doi: 10.1056/NEJMoa1009638.

74. Giugliano RP, Ruff CT, Braunwald E et al. Edoxaban versus warfarin in patients with atrial fibrillation. N Engl J Med 2013; 369: 2093-2104. doi: 10.1056/NEJMoa1310907.

75. Hankey GJ, Patel MR, Stevens SR et al. Rivaroxaban compared with warfarin in patients with atrial fibrillation and previous stroke or TIA: a subgroup analysis of ROCKET AF. Lancet Neurol 2012; 11: 315-322. doi: 10.1016/S1474-4422(12)70042-X.

76. Undas A, Pasierski T, Windyga J, Crowther M. Practical aspects of new oral anticoagulant use in atrial fibrillation. Pol Arch Med Wewn 2014; 124: 124-135.

77. Kornej J, Potpara T, Lip GY. Anticoagulation management in nonvalvular atrial fibrillation: current and future directions. Pol Arch Med Wewn 2013; 123: 623-634.

78. Garcia D, Barrett YC, Ramacciotti E, Weitz JI. Laboratory assessment of the anticoagulant effects of the next generation of oral anticoagulants. J Thromb Haemost 2013; 11: 245-252. doi: 10.1111/jth.12096.

79. Czubek U, Góralczyk T, Zalewski J, Undas A. Monitoring of anticoagulant effects of dabigatran in everyday practice: first experience in 32 Polish patients. Pol Arch Med Wewn 2014; 124: 487-489.

80. Zalewski J, Rychlak R, Góralczyk T, Undas A. Rivaroxaban concentration in patients with deep vein thrombosis who reported thrombus progression or minor hemorrhagic complica- 
tions: first Polish experience. Pol Arch Med Wewn 2014; 124: 553-555.

81. Walenga JM, Adiguzel C. Drug and dietary interactions of the new and emerging oral anticoagulants. Int J Clin Pract 2010; 64: 956-959. doi: 10.1111/j.1742-1241.2009.02286.x.

82. Mahan CE. Practical aspects of treatment with target specific anticoagulants: initiation, payment and current market, transitions, and venous thromboembolism treatment. J Thromb Thrombolysis 2015; 39: 295-303. doi: 10.1007/s11239-0141164-4.

83. Palareti G, Cosmi B. Bleeding with anticoagulation therapy Who is at risk, and how best to identify such patients. Thromb Haemost 2009; 102: 268-278. doi: 10.1160/TH08-11-0730.

84. Bourbeau J, Bartlett SJ. Patient adherence in COPD. Thorax 2008; 63: 831-838. doi: 10.1136/thx.2007.086041.

85. White HD, Gruber M, Feyzi J et al. Comparison of outcomes among patients randomized to warfarin therapy according to anticoagulant control - results from SPORTIF III and IV. Arch Intern Med 2007; 167: 239-245.

86. Goodman SG, Wojdyla DM, Piccini JP et al. Factors associated with major bleeding events: insights from the ROCKET AF trial (rivaroxaban once-daily oral direct factor Xa inhibition compared with vitamin $\mathrm{K}$ antagonism for prevention of stroke and embolism trial in atrial fibrillation). J Am Coll Cardiol 2014; 63: 891-900. doi: 10.1016/j.jacc.2013.11.013.

87. Hylek EM, Held C, Alexander JH et al. Major bleeding in patients with atrial fibrillation receiving apixaban or warfarin. The ARISTOTLE trial (apixaban for reduction in stroke and other thromboembolic events in atrial fibrillation): predictors, characteristics, and clinical outcomes. J Am Coll Cardiol 2014; 63: 2141-2147. doi: 10.1016/j.jacc.2014.02.549.

88. Antithrombotic Trialists' Collaboration. Collaborative meta-analysis of randomised trials of antiplatelet therapy for prevention of death, myocardial infarction, and stroke in high risk patients. BMJ 2002; 324: 71-86.

89. Dziewierz A, Siudak Z, Rakowski T et al. Relationship between chronic obstructive pulmonary disease and in-hospital management and outcomes in patients with acute myocardial infarction. Kardiol Pol 2010; 68: 294-301.

90. Sin DD. The devastating power of platelets in COPD exacerbations: can aspirin save lives in COPD? Thorax 2014; 69 : 603-604. doi: 10.1136/thoraxjnl-2014-205329. 